\title{
Correction to: Effects of Brazil nut consumption on selenium status and cognitive performance in older adults with mild cognitive impairment: a randomized controlled pilot trial
}

\author{
Barbara Rita Cardoso ${ }^{1}$. Daniel Apolinário ${ }^{2}$ - Verônica da Silva Bandeira ${ }^{1}$ - Alexandre Leopold Busse ${ }^{2}$. \\ Regina Miksian Magaldi ${ }^{2}$. Wilson Jacob-Filho ${ }^{2}$. Silvia Maria Franciscato Cozzolino ${ }^{1}$
}

Published online: 5 January 2021

(c) Springer-Verlag GmbH Germany, part of Springer Nature 2020

\section{Correction to: Eur J Nutr (2016) 55:107-116 \\ https://doi.org/10.1007/s00394-014-0829-2}

Unfortunately, the given name and family name of the author Barbara Rita Cardoso was incorrectly tagged in the xml data, therefore it is abbreviated wrongly as "R Cardoso B" in Pubmed. The correct given name is Barbara Rita and family name is Cardoso.

Barbara Rita Cardoso

baritacardoso@gmail.com; barbaracardoso@usp.br

1 Department of Food and Experimental Nutrition, Faculty of Pharmaceutical Sciences, University of São Paulo, Av. Prof. Lineu Prestes 580, Bloco 14, Butantã, São Paulo 05508-000, Brazil

2 Geriatrics Division, Department of Internal Medicine, University of São Paulo Medical School, São Paulo, Brazil 